УДК 563.1

04.00.00 Геолого-минералогические науки

АНАЛИЗ ДИНАМИКИ ИСЧЕЗНОВЕНИЯ И
ПОЯВЛЕНИЯ НОВЫХ ВИДОВ
РАДИОЛЯРИЙ В МЕЛОВОЙ И
ПАЛЕОГЕНОВЫЙ ПЕРИОДЫ

Агарков Юрий Васильевич

Кандидат геол.-мин. наук, доцент

SPIN-код=5345-8706

e-mail: snic@sochi.com

yagarkov2011@yandex.ru

Агарков Андрей Юрьевич

ФГБНУ Сочинский научно-исследовательский центр РАН (СНИЦ РАН), Сочи, Россия

3540000 г. Сочи, ул. Театральная $8 a$

e-mail:snic@sochi.com

aagarkov77@mail.ru

Определена динамика изменения видового богатства радиолярий на протяжении последних 150 млн. лет с точностью до геологического века. Установлены основные закономерности смены видов и таксонов высокого ранга для границы мела и палеогена. Выявлены типоморфные особенности биполярных видов перешедших из мела в палеоген и ставших прорадителями кайнозойской радиоляриевой фауны. Изменение численности видов на границе мелового и палеогенового периодов, а также существенные колебания видового богатства в палеоцене и эоцене связано с сочетанием целого ряда факторов. Наиболее важными из них являются геологические процессы, приводящие к обширным трансгрессиям и регрессиям, колебания климата, общая направленная эволюция биоты Земли и конкурентная борьба за важные химические компоненты для жизнедеятельности радиолярий. С позднемеловой эпохой связано появление на суше мощных тропических лесов с их огромной биопродуктивностью и биохимическим выветриванием. Последние привело к повышению поступления растворенного материала в бассейн седиментации, что фиксируется по появлению классических бокситов. Поскольку окись алюминия и окись кремния геохимически связаны, мы можем утверждать и о повышении притока растворенного кремнезема спровоцировавшее развитие диатомовых водорослей, ставших конкурентами для радиолярий в борьбе за кремнезем. Последние проиграли в ней, что и привело к сокращению видов. Это не было катастрофическое явление с мгновенным вымиранием, а длительный процесс
UDC 563.1

Geological-mineralogical science

\section{ANALYSIS OF EXTINCTION AND EMERGENCE DYNAMICS OF NEW RADIOLARIA'S SPECIES IN THE CRETACEOUS AND PALEOGENE PERIODS}

Agarkov Yuri Vasilievich

Doctor of Science, Associate professor

SPIN-code $=5345-8706$

Sochi Scientific Research Centre of Russian

e-mail: snic@ sochi.com

yagarkov2011@yandex.ru

Agarkov Andrey Yurievich

Sochi Scientific Research Centre of Russian Academy

of Science, Sochi, Russia

3540000 Sochi, Teatral'naya, 8 a

e-mail: snic@ sochi.com

aagarkov77@mail.ru

The dynamics of changes in the species diversity of radiolarians during the last 150 million years with accuracy to one geological century was determined. The basic patterns of species and taxa of high rank change had been established for the boundary between Cretaceous and Paleogene. There were revealed topomorphic features of bipolar species, which have succeeded from the Cretaceous into the Paleogene and became ancestors of Cenozoic radiolarian fauna. Changes in the species number in the boundary between Cretaceous and Paleogene periods, and also significant variations in the species diversity in Paleocene and Eocene are connected to a combination of a number of factors. The most important of those factors are geological processes, causing extensive transgressions and regressions, climate variability, the overall evolution direction of the Earth biota and competition for important chemical components for the Radiolaria's livelihood. The emergence of powerful tropical forests on the land with their huge bio-production and bio-chemical erosion is connected to late Cretaceous era. This resulted increasing of the dissolved material proceeding into the sedimentation pool, what is confirmed by classical bauxites emergence. Because aluminium oxide and silicon oxide are geochemically connected, we can state as well about increasing of dissolved silica flow initiated development of Diatoms, which became competitors to Radiolaria in their battle for silica. The last ones are lost this battle, what caused the species decreasing. That was not a catastrophic event with immediate extinction, but a long process 
Ключевые слова: РАДИОЛЯРИИ, МЕЛ, ПАЛЕОГЕН, ЭВОЛЮЦИЯ, ВЫМИРАНИЕ ВИДОВ
Keywords: RADIOLARIA, CRETACEOUS,PALEOGENE, EVOLUTION, SPECIES EXTINCTION

Doi: 10.21515/1990-4665-132-102

Происхождение видов, основные закономерности эволюции и крупные биотические кризисы в развитии органического мира всегда были тесно связаны с геологической историей Земли. Вся история нашей планеты представляет собой череду часто необратимых изменений состава атмо- и гидросферы, увеличение контрастности рельефа и развитие акваторий по нарастающей линии: мелководные морские водоемы, эпиконтинентальные моря и эпиконтинентальные краевые моря и океаны.

Первая попытка провести количественный анализ разнообразия радиолярий на видовом уровне для мезозоя была предпринята Ю.В. Агарковым [1-2], а для фанерозоя в целом с точностью до эпох в совместной работе с М.С. Афанасиевой, Э.О. Амоном и Д.С. Болтовским. В фанерозойской истории развития радиолярий нами выявлены девять этапов и четыре фазы эволюции [3]:

1 фаза. Ранний палеозой: 1 этап (кембрий силур).

II фаза. Поздний палеозой: 2 этап (девон ранний карбон); 3 этап (средний карбон пермь).

III фаза. Мезозой: 4 этап (триас); 5 этап (юра); б этап (мел),

IV фаза. Кайнозой: 7 этап (палеоцен эоцен); 8 этап (олигоцен плиоцен); 9 этап (четвертичный).

Количественные исследования динамики появления и исчезновения видов на уровне геологического века ранее не проводились.

Наши предварительные исследования показали [3], что эволюция радиолярий подтипа Polycystina носила характер периодических циклических изменений, когда появление новых таксонов сменялось их расцветом, а затем вымиранием, В общей динамической модели 
циклического развития радиолярий в фанерозое отдельные простые циклы стадии, объединены в циклы более высокого порядка этапы, которые, в свою очередь, характеризуют циклы высшего порядка фазы.

На каждом этапе эволюции происходили значительные изменения состава и численности радиолярий, а также смена лидирующих групп, при этом различные таксоны развивались, в определенной степени, параллельно: от выработки общего плана строения к совершенствованию частных структур скелета. Наиболее конструктивное сочетание морфологических признаков обусловливало на определенном этапе становление новых высоких таксонов и обретение ими явных эволюционных преимуществ.

2.1 Изменение численности видов радиолярий в позднемеловую эпоху

Анализ динамики видового богатства радиолярий позднемелового и палеогенового времени основан на данных содержащихся в созданной авторами информационной системе (ИС)[4]. Ее структура и возможности описаны в первой главе настоящего отчета. Общий объем терминов в главном словаре составляет 20653 названий, относящихся к 15291 валидным видам. По данным выборки из ИС радиолярии, существовавшие в различных веках позднемеловой эпохи, составляют 1364 видов.

Изменение численности видов в абсолютных значениях для мезозойской и кайнозойской эр приведено на графике (рис. 1). Его анализ показывает, что в истории Земли на протяжении последних 150 млн лет существовало несколько веков, отличавшихся существенным увеличением видового богатства Наибольшее число видов характерно для титонского, альбского, кампанского веков и ипр-приабонского и миоценового времени. Максимальный разброс значений между максимальными и минимальными 
величинами составляет пятнадцать раз. Подобные данные могут иллюстрировать морфологическое разнообразие видов в то или иное время, но не подходят для выявления динамики видообразования из-за разной длительности геологических веков. Перерасчеты с учетом этого фактора указывают, что для части веков сохраняется лидирующее положение. Однако для альбского и сантонского веков наблюдается обратная картина (рис. 2). Отношение максимальных и минимальных значений при учете длительности меняется с пятнадцать раз всего до трех pa3.

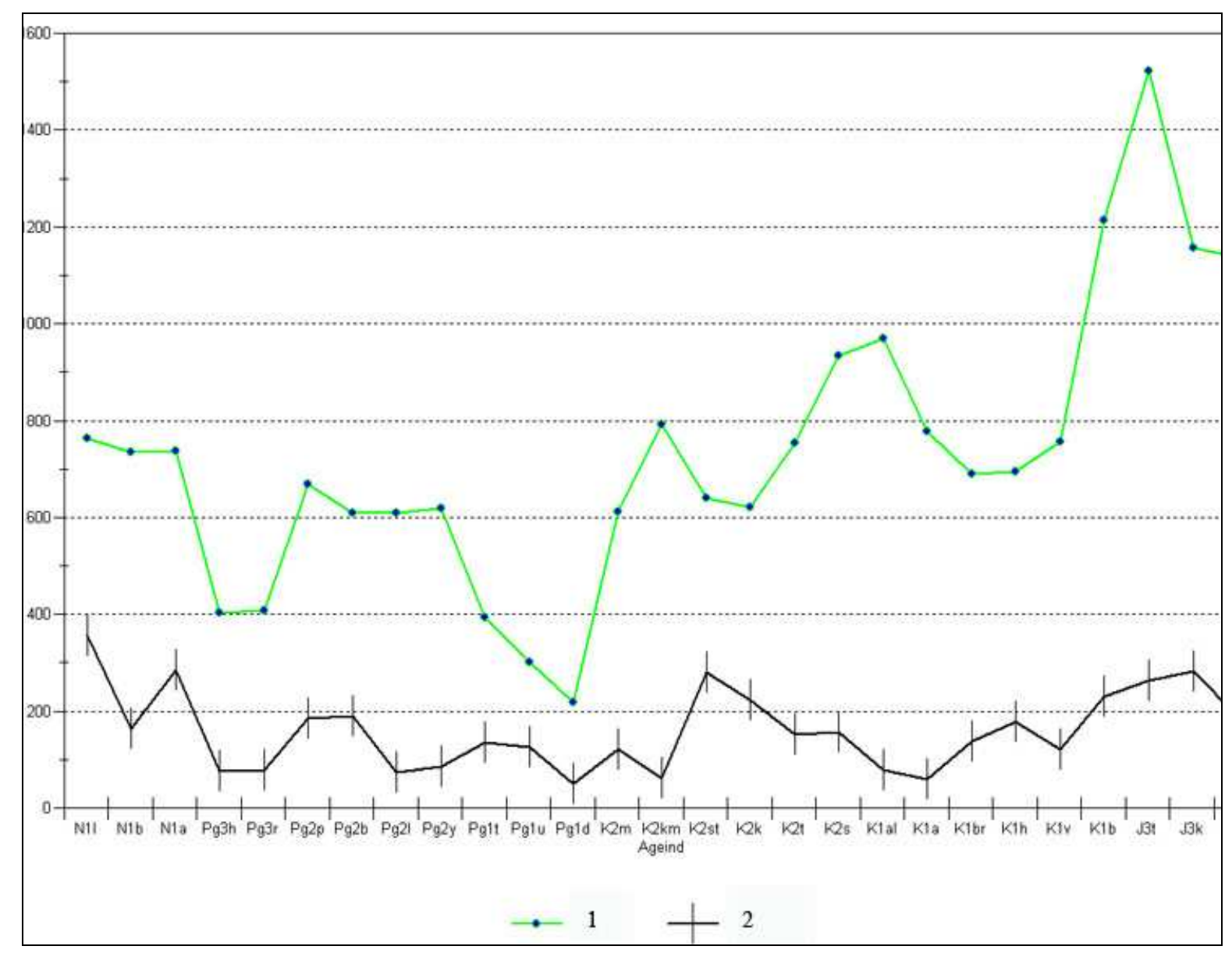

Рисунок 1 - Изменение численности видов радиолярий за последние 150 млн. лет:

1 - общее число видов; 2 - число видов/длительность века в млн. лет 
Проведенный анализ морфологии раннемеловых радиолярий показал, что они еще очень близки к юрским предкам. Для них характерно развитие многокамерных Cyrtidinata, скелеты которых с вершинной иглой орнаментированы продольными ребрами и поперечными поясами, а также распространены Acaeniotylinae с бугристыми скелетами. Очень

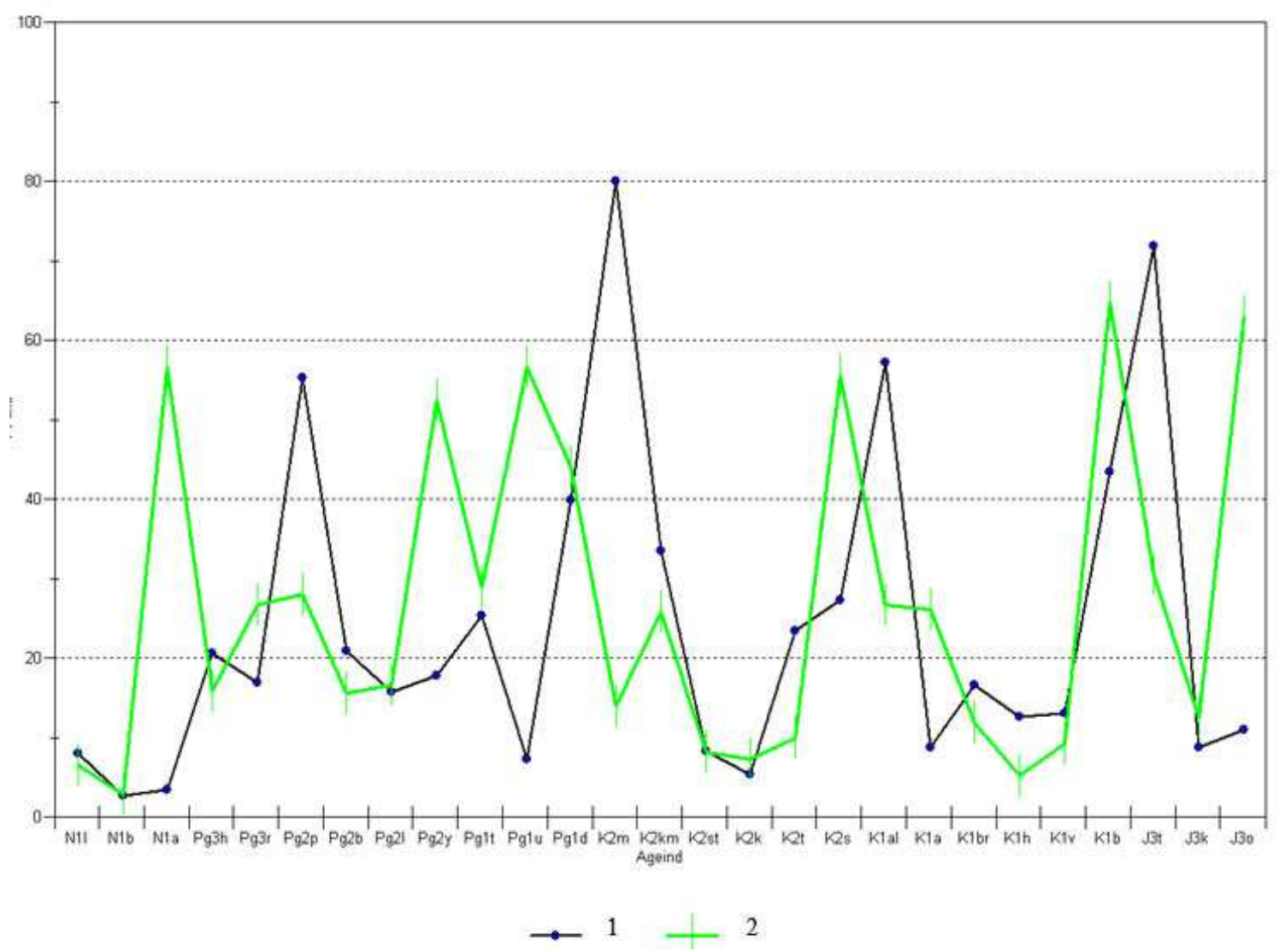

Рисунок 2 - Изменение численности видов радиолярий (в \%) за последние 150 млн. лет: 1 - исчезнувшие; 2 - появившиеся многочисленны и разнообразны ставраксонные радиолярии. Большинство семейств раннемеловых радиолярий существовало и в позднем мелу. Многие из них достигают своего расцвета только в позднем меле, но в целом для мела отмечается преобладание насселлярий $[5,6]$.

Меловой этап отличается самым высоким в фанерозое общим количеством семейств и подсемейств - 82, из которых 25 появились впервые. 
Среди иглистых Aculearia в меле продолжают существовать только Plagiacanthinae Губчатые Spumellaria представлены восемью семействами и подсемействами. $\mathrm{B}$ раннем меле отмечено появление первых Orosphaeridae. Из спумеллярий с внутренним каркасом в мелу завершают развитие Polyentactiniinae. Пористые Sphaerellaria в составе десяти семейств и подсемейств были достаточно широко распространены в меле. Среди них впервые появляются Stylosphaerinae. Ставраксонные радиолярии мела очень разнообразны и объединяют представителей 18 семейств и подсемейств, среди которых в позднем меле впервые появляются Larnacillinae, Pentapyloniinae и Spongodiscidae. Только для мелового этапа характерны Cavaspongiidae, Miropylidae и Phaseliformidae. Nassellaria мела наиболее разнообразны и насчитывают представителей 45 семейств и подсемейств, 17 из которых появились впервые, a Rotaforminae были распространены только в мелу.

Видовое разнообразие радиолярий составляло 1811 видов в раннем меле и 1364 видов в позднем. Скорость видообразования изменялась от 5.19 до 26.73 вид/млн. л. в раннюю эпоху и от 7.21 до 56.16 вид/млн. л. в позднюю эпоху. При этом средняя скорость видообразования уменьшилась до 31 вид/млн. л., т. е. почти в два раза по сравнению с юрским этапом. Общее число родов радиолярий мела составляло 515, т. е. число, сопоставимое с данными для триаса и юры. Максимум родового разнообразия приходился на поздний мел - 338 рода

В конце мела произошло вымирание 493 (80,56 \%) видов и 482 (93,1 \%) рода радиолярий. Всего же в течение мелового периода перестало существовать 32 семейства и подсемейства (39 \%), 2749 (96,56 \%) видов и $328(63,69 \%)$ родов радиолярий.

Таким образом кайнозойская история развития радиолярий начинается с 84 предков мезозойских видов. Несмотря на очевидную преемственность на границе мела и палеогена происходит резкая смена 
фаун радиолярий. В это время вымирает $80 \%$ ранее существовавших видов (рис. 2). Процесс активного вымирания начался в сантонском веке за 20 млн. лет до кризисного рубежа.

Палеоценовая эпоха характеризуется общим уменьшением количества видов до 458 и затем активным ростом в конце палеоцена и начале эоцена. Темпы вымирания находились в районе $20 \%$, что привело к общему увеличению видов в эоцене в два раза (до 926 видов). Скорость видообразования испытывала значительные колебания от 12,32 вид/млн. лет (лютеет до 71,25 вид/млн. лее (зеландий).

Морфологическое разнообразие сокращается также значительно, как и общая численность. Иглистые Aculearia в палеоцене и эоцене представлены только Plagiacanthinae.

Разнообразие губчатых Spumellaria сокращается до семи семейств и подсемейств, среди которых впервые появляются Aхopruninae, Многие роды меловых спумеллярий достигают расцвета в палеогене и постепенно становятся доминирующей группой [6].

Разнообразие пористых Sphaerellaria также уменьшается до семи семейств и подсемейств. Среди них типично палеоцен эоценовые Entapiinae и первые Heliodiscidae. Ставраксонные радиолярии испытали в конце мела массовое вымирание исчезают десять семейств и подсемейств (55,6 \%), Stauraxonaria палеоцена эоцена объединяют представителей 15 семейств и подсемейств, среди которых впервые появляются Suttoniidae, Pyloniidae (Pyloniinae, Pylodiscinae), Larnacillidae (Circodiscinae, Cryptolarnaciinae, Histriastrinae) и Coccodiscidae, Представители Palaeotetrapylinae известны только в палеоцене. Nassellaria палеоцена эоцена насчитывают 41 семейство и подсемейство, среди которых 12 появилось вновь. Характерные для юры и мела многокамерные насселлярии вымирают и уступают место одно, двух и трехкамерным скелетам 
Пережившие массовое вымирание виды можно представить четырьмя группами по пространственному распространению:

1. Виды северного полушария имевшие широкое распространение - $29 \%$

2. Виды северного полушария имеющие небольшие ареалы развития (эндэмики) - $30 \%$

3. Виды южного полушария имеющие небольшие ареалы развития (эндэмики) - 8.5\%

4. Биполярные виды - $32.5 \%$

Высокая относительная численность биполярных видов на границе мела и палеогена в истории Земли является уникальной. По данным изучения современных радиолярий биполярными являются 32 вида [7], что составляет всего 4,5 \%. Вероятно, это связано тем, что биполярные виды, переместившиеся на огромные расстояния, были самими устойчивыми к изменению обстановок обитания и соответственно к серьёзным изменениям на границе массового вымирания. Они имели компактный скелет в подавляющем большинстве случаев полностью лишенный игл и других морфологических элементов (рис.3).

Изменение численности видов на границе мелового и палеогенового периодов, а также существенные колебания видового богатства в палеоцене и эоцене связано с сочетанием целого ряда факторов.

Наиболее важными из них являются геологические процессы, приводящие к обширным трансгрессиям и регрессиям, колебания климата, общая направленная эволюция биоты Земли и конкурентная борьба за важные химические компоненты для жизнедеятельности радиолярий.

C позднемеловой эпохой связано появление на суше мощных тропических лесов с их огромной биопродуктивностью и биохимическим выветриванием. Последние привело к повышению поступления растворенного материала в бассейн седиментации, что фиксируется по 
появлению классических бокситов. Поскольку окись алюминия и окись кремния геохимически связаны, мы можем утверждать и о повышении притока растворенного кремнезема спровоцировавшее развитие диатомовых водорослей, ставших конкурентами для радиолярий в борьбе за кремнезем. Последние проиграли в ней, что и привело к сокращению видов.

Это не было катастрофическое явление с мгновенным вымиранием, а длительный процесс. 


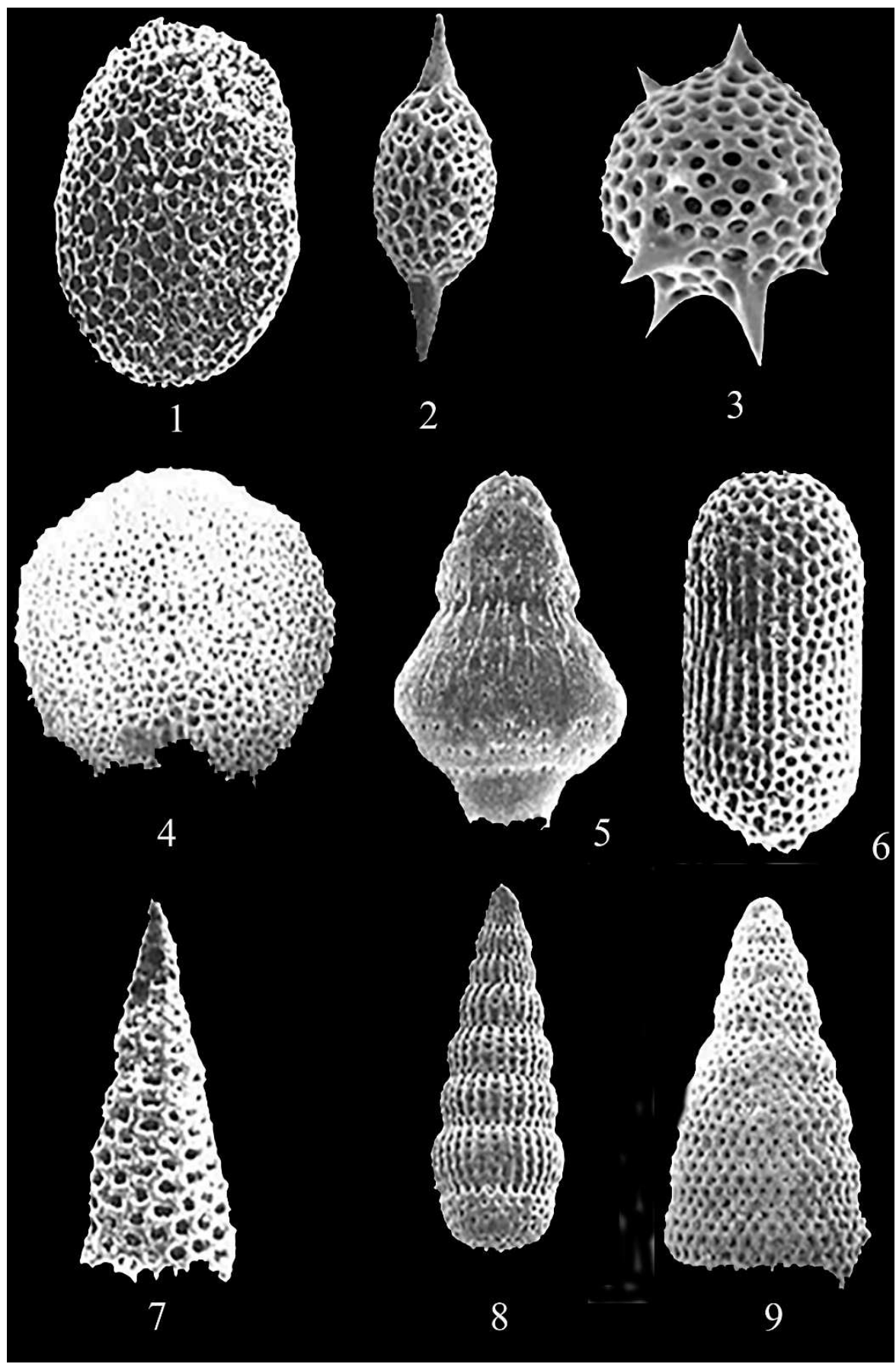

Рисунок 3 - Биполярные радиолярии (насселарии) пережившие массовое вымирание на границе меловой и палеогеновой систем: 1 Phaseliforma subcarinata Pessagno, 1975, 2 - Protoxiphotractus perplexus Pessagno 1973, 3 - Crucella aster (Lipman, 1952) Bragina 4 - Orbiculiforma renillaeformis (Campbell et Clark, 1944) Pessagno, 1976, 5 - Theocampe apicata, 6 - Theocapsomma erdnussa, 7 - Cornutella californica, 8 - Dictyomitra 
andersoni, 9 - Stichomitra compsa. Изображения по C. Hollis и L. O'Dogherty [8-9].

\section{Список литературы}

1 Агарков Ю. В. Новые данные о видовом разнообразии радиолярий мезозоя // Матер. 11 Семинара по радиоляриям (19-24 июня 2000). СПб-М, 2000. С. 910.

2 Агарков Ю.В. Этапы асинхронного и синхронного развития кремневого фито- и зоопланктона в позднем мезозое и кайнозое // Диверсификация и этапность эволюции органического мира в свете паленонтологической летописи. LX Cессия ПО. СПб, 2014. С. 23-24.

3 Radiolarians in the Geological Record / M. S. Afanasieva, E. O. Amon, Yu. V. Agarkov, D. S. Boltovskoy // Paleontological Journal. 2005. Vol. 39, Suppl. 3. 392 p.

4 Агарков Ю.В, Агарков А.Ю. Свидетельство государственной регистрации базы данных N 2017620457 от 20 апреля 2017 г.

5 Практическое руководство по микрофауне. Т. 6. Радиолярии мезозоя / Н. Ю. Брагин, В. С. Вишневская, А. И. Жамойда, Л. И. Казинцова. СПб: ВСЕГЕИ, 1999. $272 \mathrm{c}$.

6 Липман Р. Х. Руководство по изучению ископаемых радиолярий // Тр. ВСЕГЕИ. Нов. сер. Л.: Недра, 1979. Т. 256. 126 с.

7 Степаньянц С.Д., Кругликова С.Б., Бьёрклунд К.Р., Кортезе Дж. Биполярное распространение морских организмов на примере радиолярий и книдарий. Новый этап изучения проблемы // Общие вопросы морской биогеографии: Памяти акад. О.Г. Кусакина. Владивосток: Дальнаука, 2004. С. 132-181.

8 Hollis C. J. Latest Cretaceous to Late Paleocene Radiolaria from Marlborough (New Zealand) and DSDP Site 208: Ph.D. Dissertation. Auckland. University of Auckland. 1991. $308 \mathrm{p}$.

9 O'Dogherty L. Biochronology and Paleontology of Mid-Cretaceous radiolarians from Northern Apennines (Italy) and Betic Cordillera (Span) // Mem. Geol. (Lausanne). 1994. N 21. P. 1-415.

\section{References}

1 Agarkov Ju. V. Novye dannye o vidovom raznoobrazii radioljarij mezozoja // Mater. 11 Seminara po radioljarijam (19-24 ijunja 2000). SPb-M, 2000. S. 9-10.

2 Agarkov Ju.V. Jetapy asinhronnogo i sinhronnogo razvitija kremnevogo fito- i zooplanktona v pozdnem mezozoe i kajnozoe // Diversifikacija i jetapnost' jevoljucii organicheskogo mira v svete palenontologicheskoj letopisi. LX Sessija PO. SPb, 2014. S. 2324.

3 Radiolarians in the Geological Record / M. S. Afanasieva, E. O. Amon, Yu. V. Agarkov, D. S. Boltovskoy // Paleontological Journal. 2005. Vol. 39, Suppl. 3. 392 p.

4 Agarkov Ju.V, Agarkov A.Ju. Svidetel'stvo gosudarstvennoj registracii bazy dannyh N 2017620457 ot 20 aprelja $2017 \mathrm{~g}$.

5 Prakticheskoe rukovodstvo po mikrofaune. T. 6. Radioljarii mezozoja / N. Ju. Bragin, V. S. Vishnevskaja, A. I. Zhamojda, L. I. Kazincova. SPb: VSEGEI, 1999. 272 s.

6 Lipman R. H. Rukovodstvo po izucheniju iskopaemyh radioljarij // Tr. VSEGEI. Nov. ser. L.: Nedra, 1979. T. 256. 126 s.

7 Stepan'janc S.D., Kruglikova S.B., B'jorklund K.R., Korteze Dzh. Bipoljarnoe rasprostranenie morskih organizmov na primere radioljarij i knidarij. Novyj jetap izuchenija 
problemy // Obshhie voprosy morskoj biogeografii: Pamjati akad. O.G. Kusakina. Vladivostok: Dal'nauka, 2004. S. 132-181.

8 Hollis C. J. Latest Cretaceous to Late Paleocene Radiolaria from Marlborough (New Zealand) and DSDP Site 208: Ph.D. Dissertation. Auckland. University of Auckland. 1991. $308 \mathrm{p}$.

9 O'Dogherty L. Biochronology and Paleontology of Mid-Cretaceous radiolarians from Northern Apennines (Italy) and Betic Cordillera (Span) // Mem. Geol. (Lausanne). 1994. N 21. P. 1-415. 